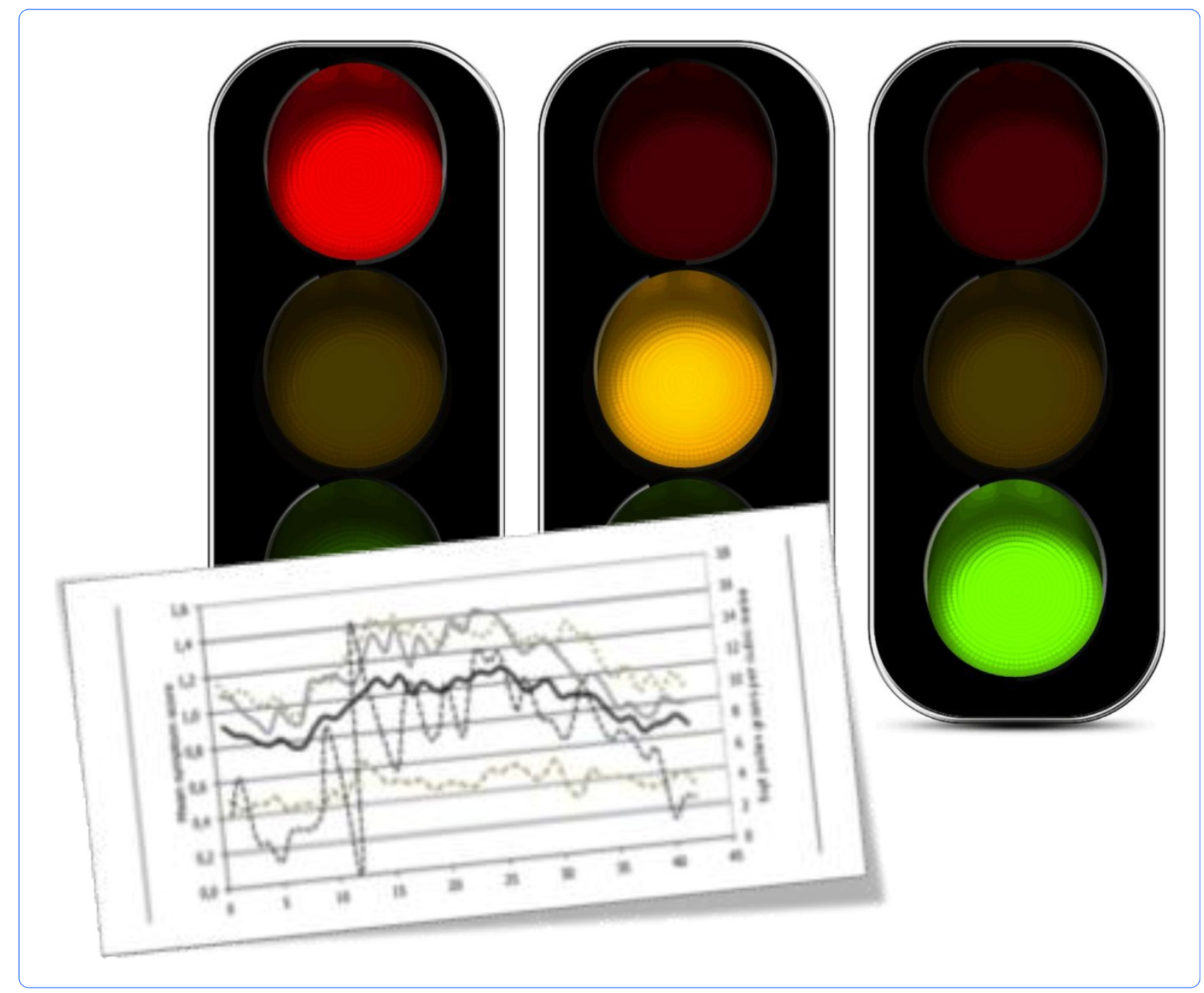

Grass pollen allergy in children and adolescentssymptoms, health related quality of life and the value of pollen prognosis

Kiotseridis et al. 


\title{
Grass pollen allergy in children and adolescents- symptoms, health related quality of life and the value of pollen prognosis
}

\author{
Hampus Kiotseridis ${ }^{1,2^{*}}$, Corrado M Cilio ${ }^{1}$, Leif Bjermer ${ }^{2}$, Alf Tunsäter ${ }^{2}$, Helene Jacobsson $^{3}$ and Åslög Dahl ${ }^{4}$
}

\begin{abstract}
Introduction: An association between pollen count (Poaceae) and symptoms is well known, but to a lesser degree the importance of priming and lag effects. Also, threshold levels for changes in symptom severity need to be validated. The present study aims to investigate the relationship between pollen counts, symptoms and health related quality of life (HRQL), and to validate thresholds levels, useful in public pollen warnings.

Material and methods: Children aged 7-18 with grass pollen allergy filled out a symptom diary during the pollen season for nose, eyes and lung symptoms, as well as a HRQL questionnaire every week. Pollen counts were monitored using a volumetric spore trap.

Results: 89 (91\%) of the included 98 children completed the study. There was a clear association between pollen count, symptom severity and HRQL during the whole pollen season, but no difference in this respect between early and late pollen season. There was a lag effect of 1-3 days after pollen exposure except for lung symptoms. We found only two threshold levels, at 30 and 80 pollen grains $/ \mathrm{m}^{3}$ for the total symptom score, not three as is used today. The nose and eyes reacted to low doses, but for the lung symptoms, symptom strength did hardly change until 50 pollen grains $/ \mathrm{m}^{3}$.

Conclusion: Grass pollen has an effect on symptoms and HRQL, lasting up to 5 days after exposure. Symptoms from the lungs appear to have higher threshold levels than the eyes and the nose. Overall symptom severity does not appear to change during the course of season. Threshold levels need to be revised. We suggest a traffic light model for public pollen warnings directed to children, where green signifies "no problem", yellow signifies "can be problems, especially if you are highly sensitive" and red signifies "alert - take action".
\end{abstract}

Keywords: Grass pollen allergy, Rhinoconjunctivitis, Asthma, Quality of life, Children, Pollen forecasts

\section{Introduction}

Allergic diseases like rhinoconjunctivitis, asthma and eczema are major health problems in the western population. Although the diseases traditionally defined by the major target organ of the allergic inflammation, they are tightly linked. The allergic inflammation has components that can give rise to systemic disease manifestations $[1,2]$ E.g., 80 per cent of children with atopic dermatitis will eventually have asthma or rhinitis [3]. 30

\footnotetext{
* Correspondence: Hampus.Kiotseridis@med.lu.se

'Pediatric Clinic, Malmö, Skåne University Hospital, Lund University, Lund, Sweden

${ }^{2}$ Departments of Respiratory Medicine and Allergology, Skåne University Hospital, Lund University, Lund, Sweden

Full list of author information is available at the end of the article
}

per cent of children with rhinitis have asthma, and more than 80 per cent of children with asthma have rhinitis symptoms [4].

Airborne pollen is one of the most common triggers of allergic disease. They are formed by flowering plants, among which some are especially prone cause to allergic disease [5]. These pollen grains contain allergens that trigger the allergic inflammatory response via mast cell activation in the human mucosa of the target organs, which then give rise to a systemic reaction.

Pollen that gives rise to human disease is present in the air in northern Europe at least 6 months every year. This fact has great implications for children affected, and interferes in many aspects of their daily lives - not 
only physical and practical but also emotional [6]. The HRQL is an important aspect that should be taken into account in the clinical follow up and is recommended to be included in clinical studies [7]. Atmospheric pollen counts are considered to be positively correlated with allergic symptomatology [8]. This has then been confirmed in numerous studies [9-12] but the delay of symptoms after the exposure, the impact of earlier exposure (priming and lag effects) and possible changes in reaction patterns during the course of the season have been less often described, just as differences in reaction patterns between different organs.

The first line treatment in respiratory allergy is allergy avoidance [13]. Pollen warnings are meant to be part of a guided self-management to prevent system aggravation and help the allergy sufferers take the control of the condition. They increase awareness about the disease and its connection to ambient aeroallergen levels, and thus act in patient education. Pollen warnings should be presented to the public in a structured, easily understandable way.

The aim was to study the effect of grass pollen exposure on symptoms and HRQL during the grass pollen season, and to validate the threshold values for pollen concentration, used in pollen warnings for children.

\section{Material and methods}

Children aged 7-18 with grass pollen allergy were consecutively selected from May 2009-01-01 until 2009-0331 . The majority of patients included in the study lived in the inner city of Malmö. Some lived in the suburban areas. Most of the children were seeing a paediatrician because of their allergy. Most of them were seeking help because of rhinoconjunctivitis, asthma or both.

The diagnosis of grass pollen allergy was, in addition to the clinical history, ascertained by a positive skin prick test or by the presence of allergy specific IgE in the blood.

Patients were excluded if they had allergic symptoms caused by other allergens during the grass pollen season.

The children filled out a HRQL questionnaire at the end of the week for every week until mid-July. Every day during the study period ( $1^{\text {st }}$ June $-12^{\text {rd }}$ July) they filled out a diary for symptom severity. All were completed by the children themselves. The study was approved by the local ethics committee and informed consent was obtained from parents and subjects.

The study protocol was approved by the Coordinating Ethics Committee of Lund University.

\section{Severity assessment}

For the classification of rhinitis we used the ARIA (Allergic Rhinitis and its Impact on Asthma) guidelines [13]. These guidelines classify rhinitis as intermittent allergic rhinitis or persistent allergic rhinitis (PAR), on the basis of the duration of symptoms. The ARIA classification also classifies the severity on the basis of the presence or absence of impairment in any of 4 health-related quality of life (HRQL) items: sleep, daily activities/sport, work/school, and troublesome symptoms. According to guidelines the rhinitis was defined as mild when there was no impairment in any of these items, and moderate/severe when there was impairment in 1 or more areas [13].

For the asthma severity assessment the guidelines of the Swedish society of paediatric allergology based on medication level were used [14].

\section{HRQL}

As a measure of HRQL the Pediatric allergic disease quality of life questionnaire (PADQLQ) was used. The total score covers three domains: a practical a physical and an emotional domain. The questions are answered with a figure (0-6) where 0 means "not troubled at all" and 6 means extremely troubled. The minimal important difference of the total score (0-6) is 0.2[15]. The instrument is validated and used in English and Swedish $[16,17]$ The questions were answered by the child.

\section{Symptom scores}

The children used a symptom diary for assessing severity on a daily basis on symptoms from eye, nose and lungs. The severity scale included four categories: no symptoms (0), mild symptoms [1], moderate symptoms [2] and severe symptoms [3].

\section{Pollen counts}

Daily atmospheric pollen counts for the Malmö area, comprising mainly urban and agricultural land in the North-European nemoral vegetation zone, were monitored during the pollen season 2009 using a Burkard 7day volumetric spore trap, situated at a roof top about $25 \mathrm{~m}$ above ground at Skåne University Hospital (SUS), $55^{\circ} 60^{\prime} \mathrm{N}, 13^{\circ} 00^{\prime} \mathrm{E}$. The exposed tapes were analysed by Botaniska Analysgruppen i Göteborg AB. The counts are representative for an area with a radius of $30 \mathrm{~km}$ from the trap, encompassing the residence of all subjects in the study.

\section{Statistical methods}

To estimate the association between pollen counts symptoms, HRQL and lag effects mixed models on repeated observations were performed. Three different symptoms (nose, eye and lung), the mean of the three different symptoms (total) and HRQL were used as outcome. The outcomes were on ordinal scales; the symptoms $0-3$ and HRQL 0-6. The pollen counts were tested as fixed effect and were analysed both as continuous and categorical variables (threshold levels). Lag effects were also tested. The 
analyses were performed on the whole period (day 1-42) and on three sub-periods (day $8-17,18-27$ and day $28-37)$. The change in reactivity to pollen exposure during the pollen season were analyzed for two periods (day 1-7 and $36-42)$. Period $(1=$ day $1-7$ and $2=36-42)$ was added to the model. The estimates were obtained by the procedure GENMOD in SAS.

Breaking points for the symptom score (nose, eye, lung and total) were obtained by the fitting method Loess in SPSS. $50 \%$ of points to fit and kernel Epanechnikov were used.

The statistical analyses were performed in SPSS Statistics 18 for Windows (IBM Corporation, Somers, NY, USA) and SAS 9.2 for Windows (SAS Institute Inc., Cary, NC, USA). A p-value below 0.05 was considered statistically significant.

\section{Results}

Patient population

98 children aged 7-18 years were enrolled into the study. 89 (91\%) completed the study. $89.8 \%$ had seasonal allergic rhinoconjunctivitis and $60.2 \%$ suffered from seasonal allergic asthma. Of the patients with rhinitis, $85.1 \%$ was classified as moderate/severe. A majority of the rhinitis patients also had concomitant asthma (61.5\%) (Table 1).

\section{The pollen season}

The first grass pollen was registered 26 April (Figure 1). From 5 May, grass pollen was registered on five days on a row. On 25 May, the grass pollen count was 4 pollen grains per cubic meter, but then, counts started to increase and on 31 May, the day before the start of the study period the pollen count was 30 pollen grains $/ \mathrm{m}^{3}$. During the study period, the pollen count varied between 1 and 242 pollen $/ \mathrm{m}^{3}$. The total number of registered pollen during the study period was 2920 , i.e. $79 \%$ of the total pollen index (3700) during the entire grass flowering period. The study period encompassed most of the anthesis of species belonging to the subfamily Pooideae, which are the main provokers of grass pollen induced allergy in Sweden [18]. The peak occurred at 13 June (Figure 1), the day after a heavy rain, and counts then did not decrease below 50 grains $/ \mathrm{m}^{3}$ until 5 July. The values for the $1^{\text {st }}$ quartile, median, and $3^{\text {rd }}$ quartile were 17,61 , and 107 pollen grains per cubic meter, respectively. After the end of the study period, the maximum daily count was 33 pollen $/ \mathrm{m}^{3}$, and the weather turned cooler with more precipitation.

\section{Relationship between pollen count and symptoms}

The breaking points for total symptom aggravation were visually inferred from a Loess curve (Figure 2). We found two sharp inflexion points at 30 and 80 pollen $/ \mathrm{m}^{3}$, and a
Table 1 Subject characteristics

\begin{tabular}{|c|c|c|}
\hline Diagnosis & $\begin{array}{l}\text { Median } \\
\text { (min-max) or }\end{array}$ & Missing values \\
\hline Characteristic & $\%$ & $\mathbf{n}$ \\
\hline \multicolumn{3}{|l|}{ Rhinoconjunctivitis and asthma $(n=89)$} \\
\hline Age & $13(7-18)$ & 0 \\
\hline Rhinitis & 89.8 & 1 \\
\hline Food allergy & 39.1 & 2 \\
\hline Asthma & 60.2 & 1 \\
\hline Eczema & 37.2 & 3 \\
\hline \multicolumn{3}{|l|}{ Rhinoconjunctivitis ( $n=79$ ) } \\
\hline Classification & & 5 \\
\hline Mild intermittent & 1.4 & \\
\hline Mild persistent & 0.0 & \\
\hline Moderate/severe intermittent & 13.5 & \\
\hline Moderate/severe persistent & 85.1 & \\
\hline Asthma & 61.5 & 1 \\
\hline Affected sleep & 71.2 & 6 \\
\hline Affected school performance & 62.9 & 9 \\
\hline Troublesome symptoms & 97.3 & 5 \\
\hline Daily activity & 81.7 & 8 \\
\hline Multiple sensitisation & 61.1 & 7 \\
\hline Immunotherapy & 3.8 & 0 \\
\hline Oral steroid & 0.0 & 0 \\
\hline Antihistamine & 93.7 & 0 \\
\hline Antihistamine nose & 16.5 & 0 \\
\hline Nasal steroid & 53.2 & 0 \\
\hline Antihistamine eye & 45.6 & 0 \\
\hline Cromoglycate eye & 28.2 & 1 \\
\hline \multicolumn{3}{|l|}{ Asthma $(n=53)$} \\
\hline Asthma grade & & 0 \\
\hline 1 & 18.9 & \\
\hline 2 & 24.5 & \\
\hline 3 & 56.6 & \\
\hline Rhinitis & 92.3 & 1 \\
\hline ICS & 90.6 & 0 \\
\hline Antileukotriene & 18.9 & 0 \\
\hline
\end{tabular}

less clear one at 150 pollen $/ \mathrm{m}^{3}$. There was a significant relationship for the total symptom scores on pollen count when calculated for the entire study period $(\mathrm{p}<$ $0.0001)$, the period comprising study days $8-17(\mathrm{p}=$ 0.0011 ), and for the period comprising study days $28-37$ $(\mathrm{p}=0.037)$.

Nose symptom scores increased continuously and linearly with pollen counts from concentrations of 0-30 grains $/ \mathrm{m}^{3}$ (Figure 2), wherefrom symptom severity increased faster until about 80 pollen $/ \mathrm{m}^{3}$. At higher pollen 
concentrations, the severity of symptoms did not appear to increase. There was a dependence on pollen count during the entire study period, during days 1-42 and during days 8-17 (for both, $\mathrm{p}<0.0001$ ). During the period days $28-37$, the dependence was near significance $(\mathrm{p}=0.066)$.

Eye symptom scores increased with pollen count beyond concentrations of about 70 grains $/ \mathrm{m}^{3}$ and did not level out until about $140-150$ pollen $/ \mathrm{m}^{3}$ Two lower inflexion points of the curve were located at pollen concentrations of about 30 and about 80 pollen $/ \mathrm{m}^{3}$ (Figure 2). The dependence of symptoms on pollen count was significant when calculated for the entire study period $(\mathrm{p}<0.0001)$. For the final period (days $28-$ $37)$, the relationship was near significance $(\mathrm{p}=0.074)$.

Lung symptoms scores related to increasing pollen counts in a pattern different from that of the nose and the eyes (Figure 2). There was no apparent change in symptom severity until levels above 50 pollen $/ \mathrm{m}^{3}$. From levels above about 70 pollen $/ \mathrm{m}^{3}$, the increase appeared almost linear. During the period days $1-42$, there was a dependence of symptoms on pollen counts $(\mathrm{p}=0.0025)$.

\section{Lag effects, accumulation of exposure effects and symptom severity}

Pollen exposure had a significant effect on nose, eyes and lung symptoms. With an increasing lag of 1-3 days, significance levels decreased. For lung symptoms, the effect was nearly significant $(p=0.055)$ for a lag of one day but with two or three days, there was none. For nose and eye symptoms, the effect of exposure 3 days before symptom registration was still significant, but significance level had decreased from $\mathrm{p}<0.0001$ for a lag of $0-$ 2 days to $\mathrm{p}=0.0021$ for nose and $\mathrm{p}=0.0007$ for eyes. For total symptoms, the significance level at a lag of 3 days decreased to $\mathrm{p}=0.0014$.

If the day when symptoms were registered was excluded, and only accumulated pollen sum during three days preceding this date was included, there was still a strongly significant effect on nose, eye and total symptoms ( $\mathrm{p}<0.0001)$, but none on lung symptoms. With an extension to five days before registration day, the effect remained strongly significant for eye symptoms, and significant to a lower degree for nose and total symptoms $(\mathrm{p}=0.0004$, and $\mathrm{p}=0.0001$, respectively).

\section{Reactivity late in pollen season}

The change in reactivity to pollen exposure during the pollen season was analysed for two periods (day 1-7 and day 36-42). The change in symptom severity by pollen exposure did not change significantly during the season neither for nose, eyes, lungs and total symptom score.

\section{Threshold levels}

We considered the nose, eye, lung and total symptom scores separately, and related symptom scores to Swedish and British/Danish pollen warning threshold levels (Table 2). We related them to a three-level alert system defined from the visual inference of the Loess curve (Figure 2), which we call the "traffic light system" with green, yellow, and red light, in order to easily communicate the symptom risk level to children (Figure 3).

\section{Lag effects, accumulation of exposure effects, and estimation of HRQL}

The mean PADQLQ score during the first study week was 1,35 and then increased to 1.4 during the fourth week Thereafter, the estimated scores decreased, to 1.1

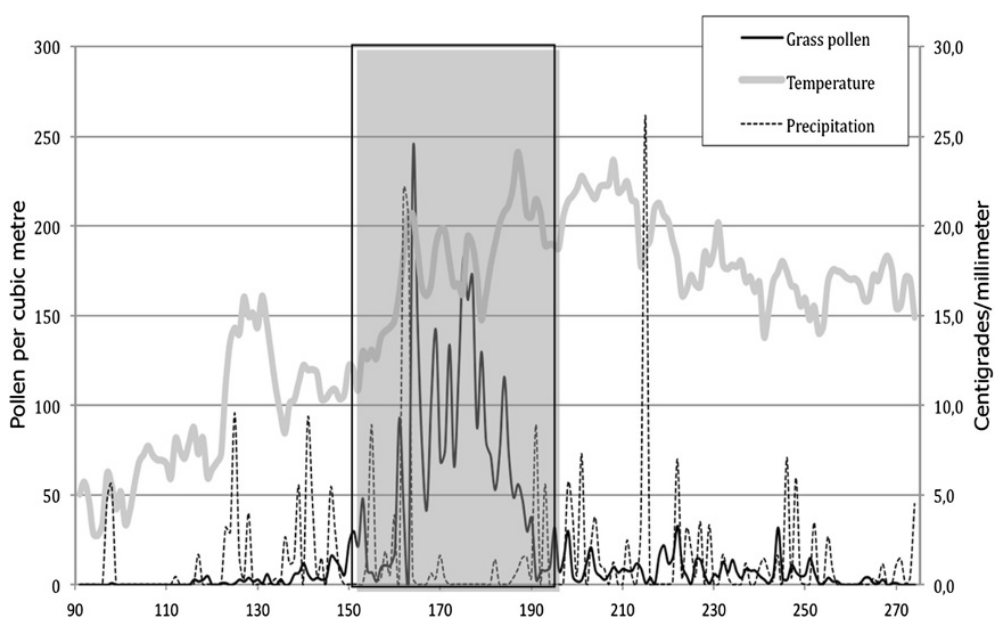

Figure 1 Daily pollen grains, maximum temperatures and precipitation in Malmö 2009. The study period 1 June-12 July (ordinal dates 152-193) is delimited with a pale blue square. 


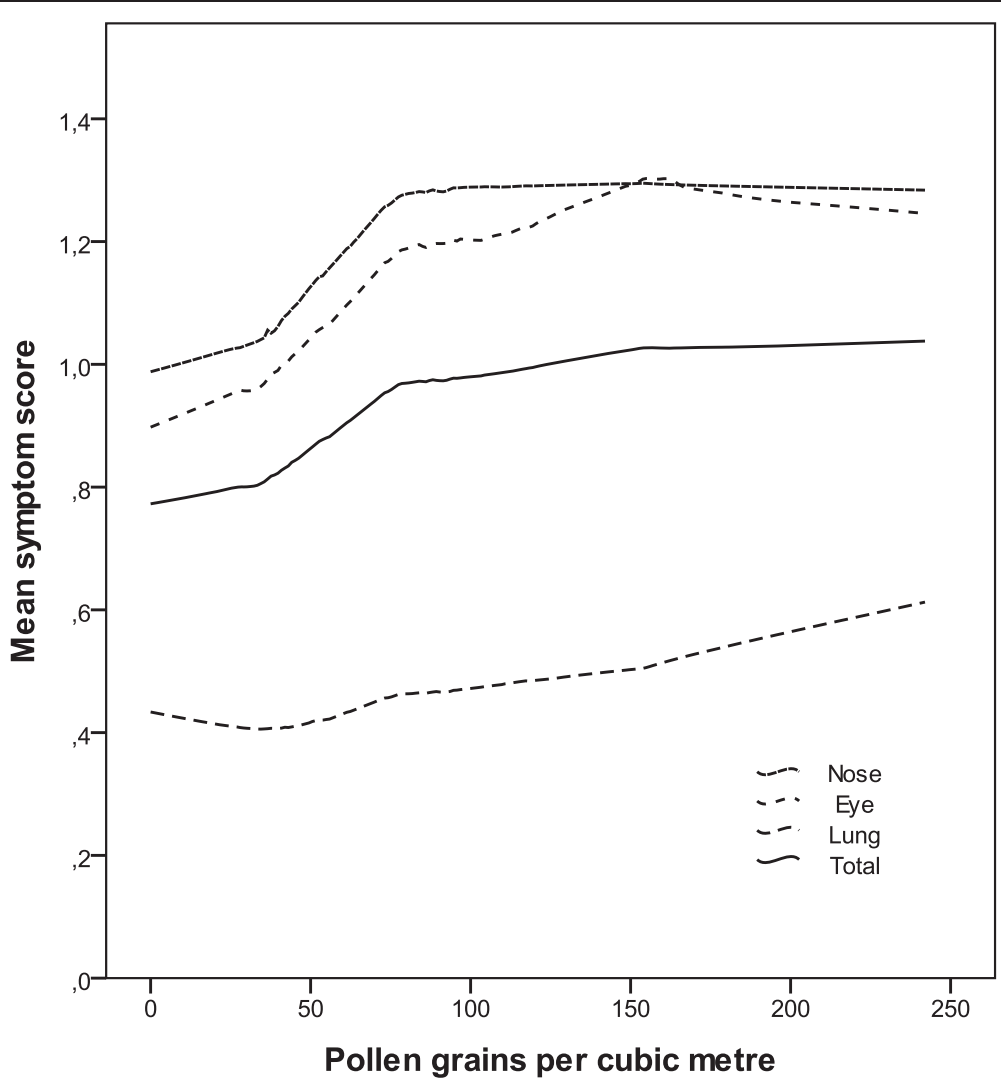

Figure 2 The relationship between symptom scores and pollen grains during the study period 1 June-12 July in Malmö 2009, evaluated with locally weighted regression (LOESS).

during the fifth week ( $29^{\text {th }}$ June- $5^{\text {th }}$ July, days $28-35$ ) and 1.0 during the last week $\left(6^{\text {th }}\right.$ July- $12^{\text {th }}$ July, days 36-42), concomitant with a generally decreasing trend in pollen concentration (Figure 4).

Pollen exposure during the days previous to the day when HRQL was estimated had an effect on the estimate, but less so, the more days that were included, and if the pollen counts on the estimation day was excluded. The strongest effect was found for the effect of the pollen count with a lag of 1 day $(p=0.0022)$. Pollen count during the single days 2 days, and 3 days before estimation day respectively, had no significant effects. The accumulated effect of four days, including registration day, or of 6 days, including estimation day, was significant $(\mathrm{p}=0.0024$, and $\mathrm{p}=0.0034$, respectively). If estimation day was excluded, and 3 days accumulated exposure or 5 days accumulated exposure were considered, the effects had significance levels of $\mathrm{p}=0.0087$ and $\mathrm{p}=0.01$, respectively. Mean pollen count during an entire week, estimation day included (days 0-6) had a significant effect $(\mathrm{p}=0.010)$ on the estimation of HRQL score.

\section{Symptom severity over time}

During the first ten days of the study, maximum symptom scores varied between 7 and 8 . They varied between 8 and 9 during the period 8-28 June (when pollen concentration levels generally was higher than 65 pollen $/ \mathrm{m}^{3}$, with exception for one day with heavy rain and another one, with 42 pollen $/ \mathrm{m}^{3}$. Score sums of 9 were recorded also towards the end of this period, and also a couple of days later, when pollen concentration levels temporarily rose again. Thereafter, maximum scores varied between 6 and 7, and the very last day, reached 5 (Figure 5).

\section{Discussion}

Pollen elicits symptoms in about 1 of every five persons, with a great effect both on individuals and on the society. Many people suffer in their daily lives, not being able to live the life they want, with a great effect on the quality of life. Furthermore, in the society, there are great costs for health care and medicine, and also a lot of indirect costs with absence from work and school. 
Table 2 Threshold levels

\begin{tabular}{|c|c|c|c|c|}
\hline Symptom & Threshold level & Pollen grain per cubic metre level & OR $(95 \% \mathrm{Cl})$ & P-value \\
\hline \multirow[t]{8}{*}{ Nose } & Sweden & Low-Medium & $0.98(0.84-1.13)$ & 0.74 \\
\hline & & Medium-High & $1.42(1.19-1.69)$ & $<0.0001$ \\
\hline & & High-Very high & $1.24(1.07-1.44)$ & 0.0049 \\
\hline & Britain/Denmark & Low-Medium & $1.18(1.02-1.37)$ & 0.026 \\
\hline & & Medium-High & $1.37(1.16-1.61)$ & 0.0002 \\
\hline & & High-Very high & $1.04(0.88-1.24)$ & 0.64 \\
\hline & Traffic lights & Low-Medium & $1.40(1.19-1.65)$ & $<0.0001$ \\
\hline & & Medium-High & $1.19(1.02-1.40)$ & 0.027 \\
\hline \multirow[t]{8}{*}{ Eye } & Sweden & Low-Medium & $1.02(0.89-1.18)$ & 0.77 \\
\hline & & Medium-High & $1.34(1.10-1.61)$ & 0.028 \\
\hline & & High-Very high & $1.30(1.14-1.48)$ & $<0.0001$ \\
\hline & Britain/Denmark & Low-Medium & $1.12(0.96-1.31)$ & 0.15 \\
\hline & & Medium-High & $1.38(1.17-1.62)$ & $<0.0001$ \\
\hline & & High-Very high & $1.30(1.09-1.56)$ & 0.0038 \\
\hline & Traffic lights & Low-Medium & $1.33(1.13-1.56)$ & 0.0007 \\
\hline & & Medium-High & $1.30(1.14-1.48)$ & $<0.0001$ \\
\hline \multirow[t]{8}{*}{ Lung } & Sweden & Low-Medium & $0.92(0.76-1.10)$ & 0.35 \\
\hline & & Medium-High & $1.10(0.89-1.35)$ & 0.39 \\
\hline & & High-Very high & $1.27(1.13-1.43)$ & $<0.0001$ \\
\hline & Britain/Denmark & Low-Medium & $0.95(0.83-1.10)$ & 0.51 \\
\hline & & Medium-High & $1.21(1.03-1.43)$ & 0.020 \\
\hline & & High-Very high & $1.20(1.01-1.42)$ & 0.041 \\
\hline & Traffic lights & Low-Medium & $1.02(0.85-1.23)$ & 0.82 \\
\hline & & Medium-High & $1.27(1.12-1.45)$ & 0.0003 \\
\hline \multirow[t]{8}{*}{ Total } & Sweden & Low-Medium & $1.04(0.91-1.18)$ & 0.57 \\
\hline & & Medium-High & $1.35(1.15-1.59)$ & 0.0003 \\
\hline & & High-Very high & $1.25(1.11-1.42)$ & 0.0004 \\
\hline & Britain/Denmark & Low-Medium & $1.14(1.00-1.29)$ & 0.046 \\
\hline & & Medium-High & $1.39(1.20-1.62)$ & $<0.0001$ \\
\hline & & High-Very high & $1.14(0.96-1.35)$ & 0.12 \\
\hline & Traffic lights & Low-Medium & $1.36(1.18-1.58)$ & $<0.0001$ \\
\hline & & Medium-High & $1.25(1.10-1.42)$ & 0.0008 \\
\hline
\end{tabular}

Pollen affects human beings with allergic sensitisation since they carry allergens. In sensitized children, these allergens elicit an allergic reaction in the target organ and give rise to a systemic inflammation [19]. It has recently been demonstrated that pollen grains, under physiological exposure conditions, release not only allergens but also bioactive lipids and enzymes that activate human neutrophils and eosinophils in vitro [20, 21]. In other studies, atmospheric pollen count were found to be positively correlated with allergic symptoms, drug consumption for allergic rhinitis and/or conjunctivitis [9-12], emergency visits because of asthma [22-26], and hospitalizations because of asthma [27-29]. However, not only sensitization rates but also the severity of reactions to the same pollen concentrations may vary between different regions [30]. Thus, it is important to investigate these patterns in different populations. Moreover, most studies have so far not investigated if the reactions change with time, and either focus on one target organ or lump symptoms from several organs together. In the present study, we have found a strong relation between symptoms, quality of life and grass pollen exposure. We also found that different organs react differently when pollen concentrations change, also with regard to the 


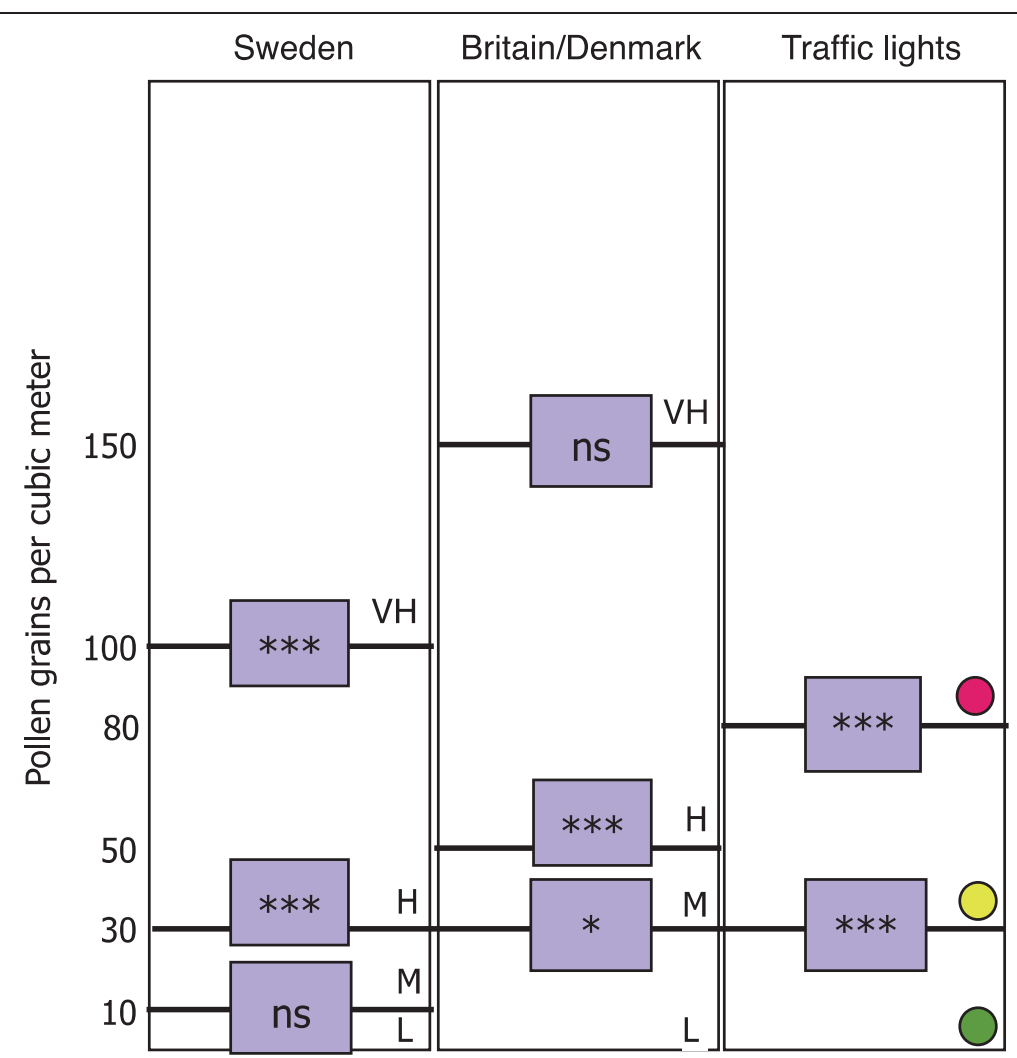

Figure 3 Threshold levels in Sweden and Britain/Denmark $(\mathrm{L}=\mathrm{Low}, \mathrm{M}=$ Medium, $\mathrm{H}=$ High and VH = Very High), and the traffic light model (Low, Medium and High). There was no significant change (ns) in symptom score between low and medium levels, when the Swedish threshold levels were used, neither was the change in symptom scores between high and very high levels as defined in the British system. ${ }^{*}=p<0.05,{ }^{* *}=p<0.01,{ }^{* * *}=p<0.001$.

effect of exposure one to three days before assessment day. There is a lag effect of the preceding days upon eye and nose, but not upon lung symptoms. We did not find any signs of aggravation, nor of symptom relief over time that could not be related to increasing or decreasing pollen levels on the assessment day or on the preceding three-day period.

Citizens who are well informed on factors in their environment, e.g., the presence of aerosols with a possible adverse effect on health, are able to take measures in order to protect themselves from these negative effects. According to EU directives, this information should not only comprise anthropogenic, but also natural sources of such aerosols [31,32]. Information about registered and forecasted amounts of allergenic and airborne pollen helps the allergy sufferer to identify his or her disease and relate it to ambient concentration levels. The allergic person can avoid activities that enhance exposure risk or demand a high level of concentration and precision, and may take appropriate medication to reduce the effects of exposure. Thus, he or she may take control of the disease, with increased performance and quality of life.
In many countries and regions, this information service is already running. Pollen concentration is measured at a daily basis, and the registered numbers and/or short-term forecasts are usually presented in media and special web sites, usually translated to categories such as low, moderate and high levels. The delimitation of these categories varies from country to country. They may either be determined according to the number of individuals that experience symptoms at a certain ambient pollen load [33], according to the severity of symptoms in an "average" allergic person, or to the general abundance of the pollen types [34]. In Malmö and other parts of Sweden, the categories used in the public warning system (Table 3) were delimitated in the 1970's, referring to "clinical experience". The capital of Denmark, Copenhagen is situated only a few kilometres from Malmö, across the strait of Öresund, and a considerable amount of inhabitants commute back and forth every day. However, in Copenhagen, the British threshold levels (Table 2) are used in public communication [35]. From an educational point of view, this situation is not desirable; first, the threshold levels should be clinically relevant, and second, the information given should not 


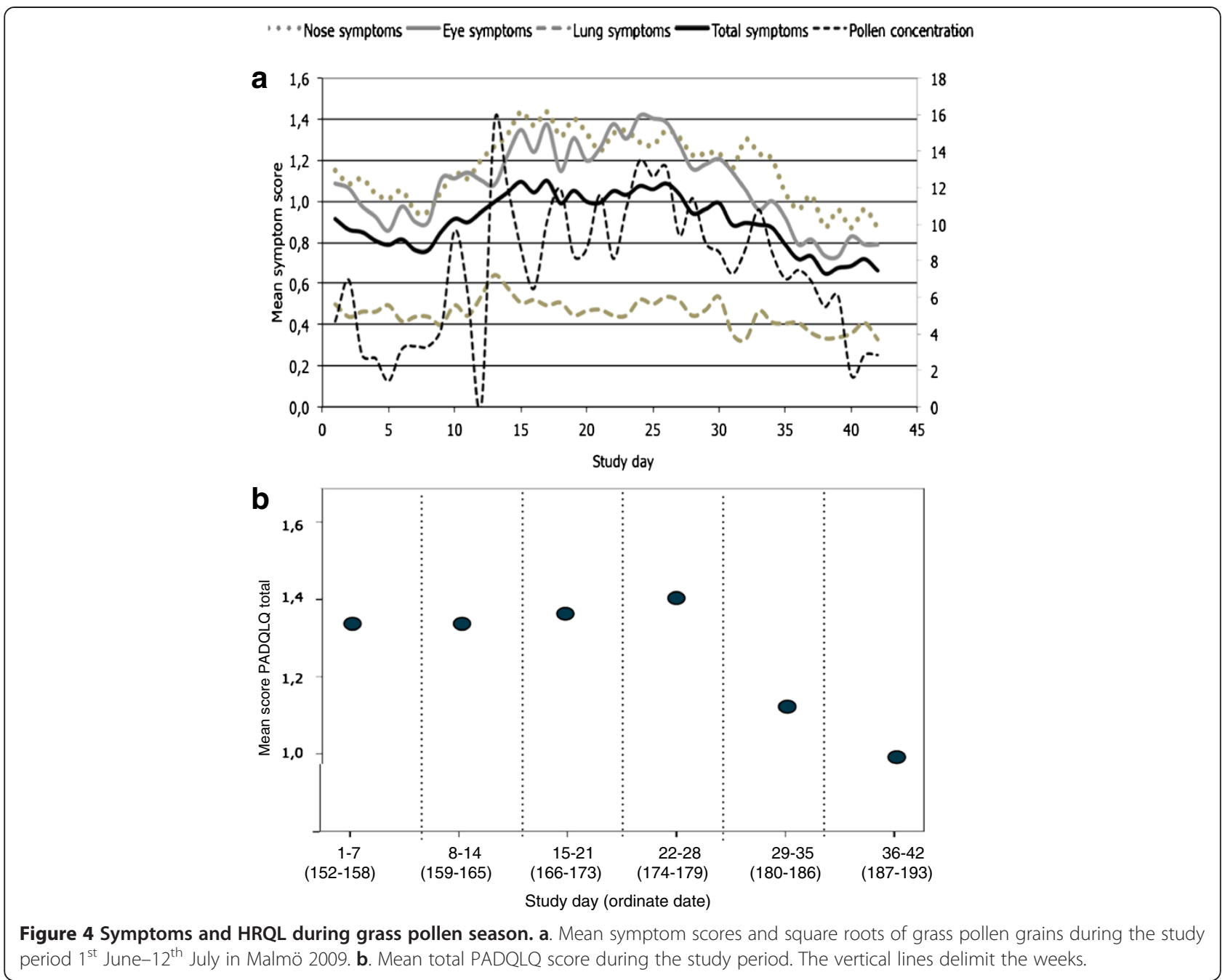

be confusing. Therefore, we wanted to investigate which of these systems, if any, reflects the clinical reactivity best.

In the children of our study group, we found three relevant levels reflecting the reaction towards grass pollen: at $0-30$ pollen per cubic meter, giving no or minor symptoms, at $30-80$ pollen per cubic meter giving intermediate symptoms, and then at more than 80 pollen per cubic meter causing severe symptoms (Figure 2). We found that the Swedish system has a unnecessary limit between "low" and "moderate" values at 10 pollen/m3, and that the British/Danish system includes a limit between "high" and "very high" levels that do not reflect any significant differences in symptom severity (Figure 3 ). We found that symptoms reached a plateau at 80 pollen $/ \mathrm{m} 3$, and we do not believe that it is clinical meaningful to further categorize into very high levels. A similar plateau beyond 80-90 pollen grains was found from France and Switzerland, which suggests that the pollen limits found in our study might be applicable in northern and central Europe [36].
Most studies on the effects of bio aerosols on health focus on asthma exacerbations, measured as emergency visits or hospitalizations, or on rhinoconjunctivitis. Fewer consider symptoms from several organs at one time. We studied total symptom scores and nose, eye and lung symptoms separately and found that the two former and the latter vary with pollen concentration in different ways. The curves describing nose and eye symptoms are steeper and have a number of more or less sharp inflexion points, whereas the lung symptoms do not increase until pollen concentration reaches about 70 pollen per cubic meter, and the symptom scores where fairly low throughout our study (Figure 2). It is possible that pollen counts must be higher to have a clear effect on lung symptoms, or that exacerbations of such symptoms are associated with special meteorological conditions, such as humid conditions and thunderstorms that may cause the pollen grains to burst. Epidemiological studies have shown an association between even lower levels of pollen concentrations (less 

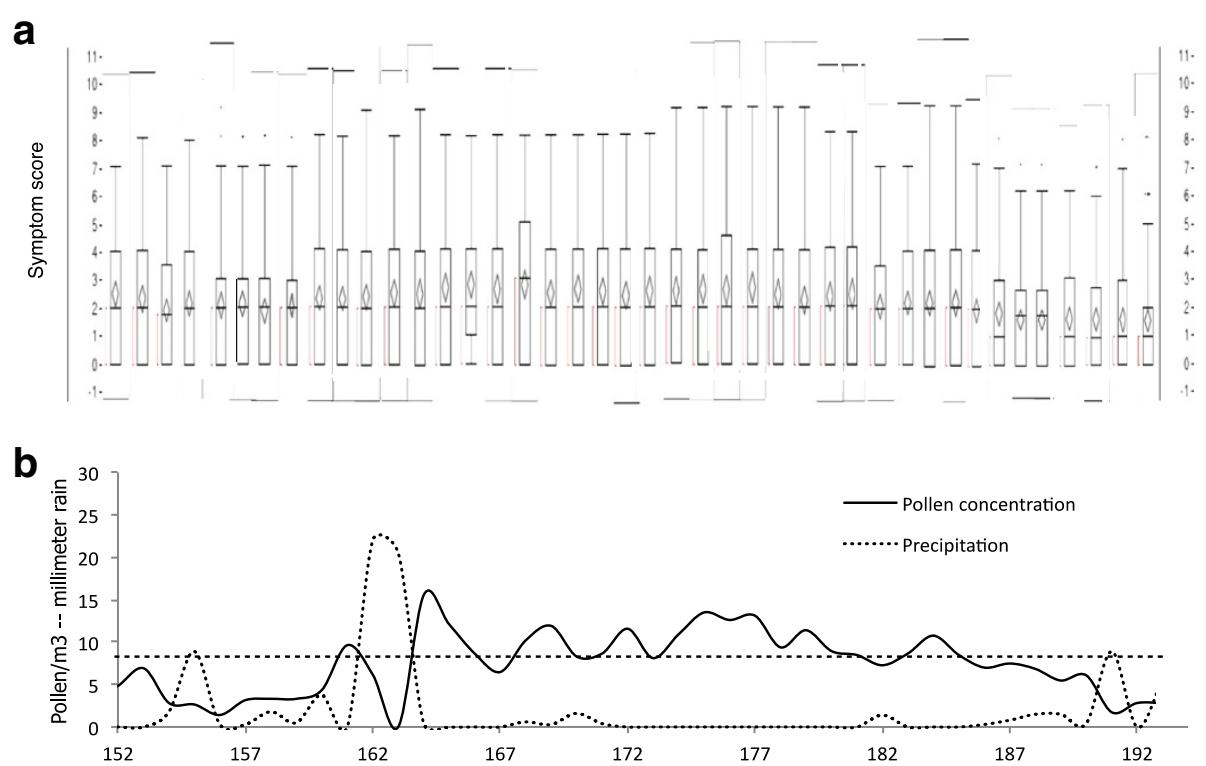

Figure 5 a. Distribution of total symptom scores for each study day during the period 1 June-12 July in Malmö 2009. Each box plot is composed of 3 horizontal lines displaying the 25th, 50th, 75 th and 90th percentiles. The dots represent outliers. $\mathbf{b}$. Sum of pollen counts and precipitation, day by day during the same period. The horizontal line denotes 80 pollen grains per cubic metre, the suggested lower limit for "high grass pollen concentration". Pollen counts are expressed as square roots of the actual numbers.

than 30 pollen grains) and hospital admissions, which suggests that these levels might have effect on susceptible individuals [37]. During the present study, there was little precipitation, with exception of one day just before the pollen peak, and the connection between heavy rains and lung symptoms could not be evaluated. But pollen-derived debris and small particles can be associated with pollen allergens, and since they are much smaller than the intact grains are themselves, they are able to penetrate into the lower airways as to induce asthma [38]. Furthermore, asthma is a complex disease with many different phenotypes where pollen allergy is only one of many factors influencing asthma control [39]. From our results, it is apparent that even if less dramatic, rhinoconjunctivitis must not be neglected, since there is a clear effect on the well being and HRQL of the involved children (Figure 4).

We found a lag effect up to 5 days. Some previous studies have found a lag phase of $1-5$ days [40, 41]. We could not find any difference in reactivity between the

Table 3 Odds Ratios for symptoms at different threshold levels between different pollen grain levels

\begin{tabular}{llll}
\hline & \multicolumn{3}{c}{ Threshold level (pollen grains per cubic metre) } \\
\cline { 2 - 4 } Levels & Britain/Denmark & Sweden & Traffic lights \\
\hline Low & $1-30$ & $0-10$ & $0-30$ \\
Moderate & $31-50$ & $11-30$ & $31-80$ \\
High & $51-150$ & $31-100$ & $81-$ \\
Very High & $150-$ & $101-$ & \\
\hline
\end{tabular}

beginning and the end of the pollen season. As early as in the 1960's, repeated pollen challenges were shown to increase nasal sensitivity to other allergens in experimental models. This was called Connell's priming effect [42]. De Weger et al. [43] found that that allergic rhinitis symptoms at similar grass pollen concentrations were more severe in the early flowering season as compared to those in the late flowering season. They suggested that there is a natural potential to down-regulate the allergic response after repeated allergen exposure, similar to the effects of successful immunotherapy. In contrast to the results of that study, we could neither find evidence for symptom relief, nor aggravation, during the course of the study period that could not be related to changes in pollen levels. The strength of our design is that we do not have symptom aggravation in early grass pollen season due to actual other allergen exposure (e.g. birch pollen), since birch senstized children were excluded.

\section{Strengths and limitations of this study}

The strength of our study is the well-characterized patient population, the wide range of symptom severity in the children included in the study, the careful follow up including HRQL and symptom diary with repeated measurements.

It would have been appropriate to have monosensitized children in order to study the effect of grass pollen exposure but this was not possible since most of our population are multisensitized. We believe that the results in the 
present study population with partially multisensitized but only symptomatic to grass pollen are valid although we cannot exclude an underlying allergic inflammation affecting the result. Also a control group would have been preferred. In this study the children are their own controls. This has been done by assessment both in and out of season. The generalizability is limited to some degree since the recruitment of patients was made on patients seeking help for their pollen allergy and thus probably not representative for the whole grass pollen allergy population. We believe that the study population are representative for the population seeking help for their grass pollen allergy and thus is of great importance to study for the optimization of their treatment.

Other factors than pollen, such as humidity, temperature and air pollution, might also influence the result. Air pollution may be an important factor working synergistically with pollen eliciting symptoms. Air pollutants can both interact with pollen grains, leading to an increased release of antigens characterized by modified allergenicity, and affect the airways, by enhancing the contact between allergens and immunoactive cells, and thus reinforce allergic inflammation [31]. Particulate pollutants can interact with allergen-carrying paucimicronic particles derived from plants. The paucimicronic particles, pollen-originated or not, are able to reach peripheral airways with inhaled air, so inducing asthma in sensitized subjects [38].

Grass pollen originates from several species, which are not readily distinguished in the traditional pollen analysis. Most grass pollen allergies in Scandinavia are said to be induced by several species within the subfamily Pooideae, with extensive cross-allergy, but species belonging to other subfamilies are also present, e.g. Phragmites, although the peak of their flowering is later. When considering the effects of grass pollen, it would be optimal to have access to more detailed phenological information and measurements of airborne allergenic proteins, to be able explain if changes in symptoms is related to allergen load or not. However, our study is likely to have encompassed most of the Pooideae flowering period and the results should reflect such a relationship. Reactivity to other pollens, like birch, still has to be validated.

Another limitation is the lack of medication score. The effect of pollen exposure should also include the medication need, which can affect both symptoms and HRQL. This is recommended in guidelines for clinical studies [7]. In the present observational study, children had a wide range of different medications and most of them used their medication regularly and thus are not believed to correlate to the burden of pollen exposure.

All the analyses presented here are conducted on group level. Web-based individual based forecasts exists, where the patient fills in a diary to estimate the sensitivity to pollen exposure will be useful, but need to be developed for optimal communication with different target groups and to suit their varying reaction patterns according to age and geographical origin.

\section{Conclusion}

Respiratory allergy is a great problem, and in case of grass pollen allergy we find an effect on symptoms and on HRQL, lasting up to 5 days after exposure. We neither find indications of symptom aggravation, nor alleviation during the course of exposure. One cornerstone in treatment in respiratory allergy and in pollen allergy is the availability of pollen forecasts to make it possible to take preventive actions. Such a system should be evidence based, and easy to understand. We suggest a traffic light model for public pollen warnings directed to children, where green means "no problem", yellow means "can be problems, especially if you are highly sensitive" and red means "alert - take action".

\section{Abbreviations}

PADQLQ: Pediatric allergic disease quality of life questionnaire; QoL: Quality of life; HRQL: Health related quality of life.

\section{Competing interests}

The authors have stated explicitly that there are no conflicts of interest.

\section{Authors contributions}

HK initiated, designed and performed the study, collected and analysed the data and wrote the paper. CC, LB, and contributed to the design of study and writing of the paper. $\mathrm{HJ}$ co-analysed the data and wrote the paper. AT and $\AA D$ contributed to the design of the study and analysis of data and the writing of the paper. All authors read and approved the final manuscript.

\section{Author details}

${ }_{1}^{1}$ Pediatric Clinic, Malmö, Skåne University Hospital, Lund University, Lund, Sweden. ${ }^{2}$ Departments of Respiratory Medicine and Allergology, Skåne University Hospital, Lund University, Lund, Sweden. ${ }^{3}$ Competence Centre for Clinical Research, Skåne University Hospital, Lund, Sweden. ${ }^{4}$ Departments of Biological and Environmental Sciences, Gothenburg University, Gothenburg, Sweden.

Received: 8 April 2013 Accepted: 3 June 2013

Published: 22 June 2013

\section{References}

1. Togias AG: Systemic immunologic and inflammatory aspects of allergic rhinitis. J Allergy Clin Immunol 2000, 106(5 Suppl):S247-S250.

2. Leynaert B, Neukirch F, Demoly P, Bousquet J: Epidemiologic evidence for asthma and rhinitis comorbidity. J Allergy Clin Immunol 2000, 106(5 Suppl):S201-S205.

3. Barnes KC: Evidence for common genetic elements in allergic disease. J Allergy Clin Immunol 2000, 106(5 Suppl):S192-S200.

4. Vignola AM, Chanez P, Godard P, Bousquet J: Relationships between rhinitis and asthma. Allergy 1998, 53(9):833-839. Epub 1998/10/27.

5. Hyde HA: Atmospheric pollen grains and spores in relation to allergy. II. Clin Allergy 1973, 3(2):109-126. Epub 1973/06/01.

6. Kiotseridis H, Cilio CM, Bjermer L, Aurivillius M, Jacobsson H, Dahl A, et al: Quality of life in children and adolescents with respiratory allergy, assessed with a generic and disease-specific instrument. Clin Respir J 2012. Epub 2012/05/25.

7. Canonica GW, Baena-Cagnani CE, Bousquet J, Bousquet PJ, Lockey RF, Malling $\mathrm{HJ}$, et al: Recommendations for standardization of clinical trials with Allergen Specific Immunotherapy for respiratory allergy. A 
statement of a World Allergy Organization (WAO) taskforce. Allergy 2007, 62(3):317-24.

8. Sack S, Brooklyn I, Golan H, Richmond M: The relationship between clinical symptoms and pollen count in pollinosis. J Allergy 1942, 13(3):296-299.

9. Takasaki K, Enatsu K, Kumagami H, Takahashi H: Relationship between airborne pollen count and treatment outcome in Japanese cedar pollinosis patients. Eur Arch Otorhinolaryngol 2009, 266(5):673-6. Epub 2008/08/16.

10. Zeghnoun A, Ravault C, Fabres B, Lecadet J, Quenel P, Thibaudon M, et al: Short-term effects of airborne pollen on the risk of allergic rhinoconjunctivitis. Arch Environ Occup Health 2005, 60(3):170-6. Epub 2006/12/13.

11. Fuhrman C, Sarter H, Thibaudon M, Delmas MC, Zeghnoun A, Lecadet J, et al: Short-term effect of pollen exposure on antiallergic drug consumption. Ann Allergy Asthma Immunol 2007, 99(3):225-31. Epub 2007/10/04.

12. Breton MC, Garneau M, Fortier I, Guay F, Louis J: Relationship between climate, pollen concentrations of Ambrosia and medical consultations for allergic rhinitis in Montreal, 1994-2002. Sci Total Environ 2006, 370(1):39-50. Epub 2006/08/11.

13. Bousquet J, Van Cauwenberge $P$, Khaltaev N: Allergic rhinitis and its impact on asthma. J Allergy Clin Immunol 2001, 108(5 Suppl):S147-334. Epub 2001/11/15.

14. Läkemdelelsverket. Information från Läkemedelsverket. 2007. Supplement 1. www.lakemedelsverket.se.

15. Roberts G, Mylonopoulou M, Hurley C, Lack G: Impairment in quality of life is directly related to the level of allergen exposure and allergic airway inflammation. Clinical and experimental allergy : journal of the British Society for Allergy and Clinical Immunology 2005, 35(10):1295-300. Epub 2005/10/22.

16. Roberts G, Hurley C, Lack G: Development of a quality-of-life assessment for the allergic child or teenager with multisystem allergic disease. J Allergy Clin Immunol 2003, 111(3):491-7. Epub 2003/03/19.

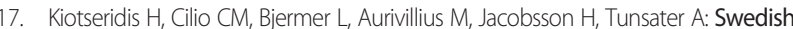
translation and validation of the Pediatric Allergic Disease Quality of Life Questionnaire (PADQLQ). Acta Paediatr 2011, 100(2):242-7. Epub 2010/09/30.

18. Andersson $\mathrm{K}$, Lidholm J: Characteristics and immunobiology of grass pollen allergens. Int Arch Allergy Immunol 2003, 130(2):87-107. Epub 2003/04/04.

19. Traidl-Hoffmann C, Kasche A, Menzel A, Jakob T, Thiel M, Ring J, et al: Impact of pollen on human health: more than allergen carriers? Int Arch Allergy Immunol 2003, 131(1):1-13. Epub 2003/05/22.

20. Plotz SG, Traidl-Hoffmann C, Feussner I, Kasche A, Feser A, Ring J, et al: Chemotaxis and activation of human peripheral blood eosinophils induced by pollen-associated lipid mediators. J Allergy Clin Immunol 2004, 113(6):1152-60. Epub 2004/06/23.

21. Traidl-Hoffmann C, Kasche A, Jakob T, Huger M, Plotz S, Feussner I, et al: Lipid mediators from pollen act as chemoattractants and activators of polymorphonuclear granulocytes. J Allergy Clin Immunol 2002, 109 (5):831-8. Epub 2002/05/08.

22. Heguy L, Garneau M, Goldberg MS, Raphoz M, Guay F, Valois MF: Associations between grass and weed pollen and emergency department visits for asthma among children in Montreal. Environ Res 2008, 106(2):203-11. Epub 2007/12/21

23. Tobias A, Galan I, Banegas JR, Aranguez E: Short term effects of airborne pollen concentrations on asthma epidemic. Thorax 2003, 58 (8):708-10. Epub 2003/07/30.

24. Tobias A, Galan I, Banegas JR: Non-linear short-term effects of airborne pollen levels with allergenic capacity on asthma emergency room admissions in Madrid, Spain. Clin Exp Allergy 2004, 34(6):871-8. Epub 2004/06/16

25. Tobias A, Saez M, Galan I, Banegas JR: Point-wise estimation of non-linear effects of airborne pollen levels on asthma emergency room admissions. Allergy 2009, 64(6):961-2. Epub 2009/01/28.

26. Carracedo-Martinez E, Sanchez C, Taracido M, Saez M, Jato V, Figueiras A Effect of short-term exposure to air pollution and pollen on medical emergency calls: a case-crossover study in Spain. Allergy 2008, 63(3):347-53. Epub 2007/12/07.

27. Dales RE, Cakmak S, Judek S, Coates F: Tree Pollen and Hospitalization for Asthma in Urban Canada. Int Arch Allergy Immunol 2008, 146(3):241-7.

28. Rosas I, McCartney HA, Payne RW, CalderÛn C, Lacey J, Chapela R, et al: Analysis of the relationships between environmental factors (aeroallergens, air pollution, and weather) and asthma emergency admissions to a hospital in Mexico City. Allergy 1998, 53(4):394-401.
29. Dales RE, Cakmak S, Judek S, Dann T, Coates F, Brook JR, et al: Influence of outdoor aeroallergens on hospitalization for asthma in Canada. J Allergy Clin Immunol 2004, 113(2):303-6. Epub 2004/02/10

30. Burbach GJ, Heinzerling LM, Edenharter G, Bachert C, Bindslev-Jensen C, Bonini S, et al: GA(2)LEN skin test study II: clinical relevance of inhalant allergen sensitizations in Europe. Allergy 2009, 64(10):1507-15. Epub 2009/09/24.

31. Klein T, Kukkonen J, Dahl A, Bossioli E, Baklanov A, Vik AF, et al: Interactions of physical, chemical, and biological weather calling for an integrated approach to assessment, forecasting, and communication of air quality. Ambio 2012, 41(8):851-64. Epub 2012/05/26.

32. Marelli L: Contribution of natural sources to air pollution levels in the EU - a technical basis for the development of guidance for the Member States. Institute for Environment and Sustainability; 2007.

33. Stewart MG: Identification and management of undiagnosed and undertreated allergic rhinitis in adults and children. Clin Exp Allergy 2008, 38(5):751-760. doi:10.1111/j.1365-2222.2008.02937.x. Review.

34. Burge HA: Monitoring for airborne allergens. Ann Allergy 1992, 69(1):9-18

35. Davies RR, Smith LP: Forecasting the start and severity of the hay fever season. Clin Allergy 1973, 3(3):263-7. Epub 1973/09/01.

36. Caillaud DM, Martin S, Segala C, Besancenot JP, Clot B, Thibaudon M: Nonlinear short-term effects of airborne Poaceae levels on hay fever symptoms. J Allergy Clin Immunol 2012, 130(3):812-4. e1. Epub 2012/06/19.

37. Erbas B, Chang JH, Dharmage S, Ong EK, Hyndman R, Newbigin E, et al: Do levels of airborne grass pollen influence asthma hospital admissions? Clinical and experimental allergy: journal of the British Society for Allergy and Clinical Immunology 2007, 37(11):1641-7. Epub 2007/09/20.

38. Bacsi A, Choudhury BK, Dharajiya N, Sur S, Boldogh I: Subpollen particles: carriers of allergenic proteins and oxidases. J Allergy Clin Immunol 2006, 118(4):844-50. Epub 2006/10/13.

39. Bush A, Menzies-Gow A: Phenotypic differences between pediatric and adult asthma. Proc Am Thorac Soc 2009, 6(8):712-9. Epub 2009/12/17.

40. Taudorf E, Moseholm L: Pollen count, symptom and medicine score in birch pollinosis. A mathematical approach. Int Arch Allergy Appl Immunol 1988, 86(2):225-33. Epub 1988/01/01.

41. Roberts G, Hurley C, Bush A, Lack G: Longitudinal study of grass pollen exposure, symptoms, and exhaled nitric oxide in childhood seasonal allergic asthma. Thorax 2004, 59(9):752-6. Epub 2004/08/31.

42. Connell JT: Quantitative intranasal pollen challenges. 3. The priming effect in allergic rhinitis. J Allergy 1969, 43(1):33-44.

43. de Weger LA, Beerthuizen T, Gast-Strookman JM, van der Plas DT, Terreehorst I, Hiemstra PS, et al: Difference in symptom severity between early and late grass pollen season in patients with seasonal allergic rhinitis. Clin Transl Allergy 2011, 1(1):18. Epub 2011/01/01.

doi:10.1186/2045-7022-3-19

Cite this article as: Kiotseridis et al:: Grass pollen allergy in children and adolescents-symptoms, health related quality of life and the value of pollen prognosis. Clinical and Translational Allergy 2013 3:19.

\section{Submit your next manuscript to BioMed Central and take full advantage of:}

- Convenient online submission

- Thorough peer review

- No space constraints or color figure charges

- Immediate publication on acceptance

- Inclusion in PubMed, CAS, Scopus and Google Scholar

- Research which is freely available for redistribution 